\title{
Authors' Reply to Moura et al.: "Safety of Janus Kinase Inhibitors in Older Patients: A Focus on the Thromboembolic Risk"
}

\author{
Suraj Rajasimhan ${ }^{1}$ (1) $\cdot$ Omer Pamuk ${ }^{2}$ James D. Katz ${ }^{2}$
}

Accepted: 24 March 2021 / Published online: 19 April 2021

(c) This is a U.S. government work and not under copyright protection in the U.S.; foreign copyright protection may apply 2021

In a letter to the editor [1] commenting on our Janus kinase article that was recently published in Drugs \& Aging [2], Moura et al. point out controversies in the interpretation of thromboembolic risk data associated with the JAK inhibitors. We appreciate their attention to the importance of not confusing an 'association' with 'causation'. Indeed, the controversy continues to be debated vigorously in recent medical literature [3]. We also appreciate Moura et al. pointing out issues concerning inhibitor specificity.

Disease-specific (e.g., systemic inflammation), patientspecific (e.g., limited mobility of arthritis patients), and environmental factors (e.g., other medication exposures) may all contribute to bias when interpreting the results of studies of the vascular complications associated with JAK inhibitors. Similarly, it may be necessary to control for transient changes in platelet levels at the time of JAK inhibitor initiation (i.e., time-varying effect). We also recognize that the reported association may be confounded not only by concomitant underlying disease (e.g., increased propensity for vascular disease in rheumatic disease patients) but other yet-to-be-defined risks such as off-target effects of JAK inhibitors on other signaling pathways [4].

The FDA black box alert for tofacitinib points to an increased risk of thrombosis for the larger 10-mg twice daily dose based upon postmarketing safety data.

This reply refers to the comment available online at https://doi.org/ 10.1007/s40266-021-00857-3 and to the original article available online at https://doi.org/10.1007/s40266-020-00775-w.

Suraj Rajasimhan

suraj.rajasimhan@nih.gov

1 Clinical Pharmacy Specialist-Pharmacotherapy, Pharmacy Department, National Institutes of Health Clinical Center, 10 Center Drive, Bldg. 10, Room 1C240, Bethesda, MD 20892, USA

2 Office of the Clinical Director, Intramural Research Program, National Institute of Arthritis and Musculoskeletal and Skin Diseases, National Institutes of Health, Bethesda, MD, USA
Exposure-response analyses suggest the receptor selectivity of JAK inhibitors is dose-dependent $[5,6]$. The doseexposure analysis among JAK inhibitors with regards to thromboembolic risk requires further exploration. Finally, and from a mechanistic standpoint, the association is additionally complex owing to the multiplicity of cytokines that are down regulated, which may vary significantly depending upon the specific member of the class of JAK inhibitors under investigation.

In the absence of mechanistic data, sorting out class and dose relationships after a medication has received FDA approval relies upon either detailed pharmacovigilance or carefully designed prospective cohort studies. Good pharmacovigilance practices must recognize the possibility of reporting bias, under-recording concurrent medications, and the failure of prescribers to adhere to standard prescribing indications [7]. To this end, we endorse the efforts of Moura et al. to illuminate the importance of not confusing association with causation, and we agree that it is important not to "paint with broad brush" an epidemiological signal.

Recently, a new concept in hematopoiesis called CHIP (clonal hematopoiesis of indeterminate potential) was defined by Jaiswal and colleagues [8]. In this condition, somatic mutations are associated with clonal expansion of hematopoietic cells without fulfilling the diagnostic criteria for a hematological malignancy [9]. One study reported an increased frequency of CHIP-associated mutations in older rheumatoid arthritis patients [10]. Previous research suggested that age-dependent somatic CHIP mutations, including JAK2 mutations, are associated with chronic inflammation, thrombotic vascular events, and malignant transformation [11]. Somatic JAK2 mutations are relatively common in older individuals, and they are associated with myeloproliferative neoplasia and thrombosis [11]. Platelets with JAK2 mutations display increased activity and hypercoagulation [12]. Many cytokines that are themselves related to thrombosis and inflammation use JAKs for signal transduction [11]. It may be speculated that age-dependent somatic 
JAK mutations may contribute to thrombosis in the older population. Moura et al. correctly point out the inhibition of JAK2 mutations could reduce the risk of thrombosis. However, some cytokines related to thrombosis and inflammation use different JAK pairings for signal transduction; for example, prothrombotic and anti-thrombotic signals are transmitted, respectively, by JAK1/TYK2 and JAK1/JAK2 [13]. Baricitinib, a selective JAK1/2 inhibitor, has shown a dosedependent increase in platelets [14]. Baricitinib inhibition of JAK2 associated with thrombopoietin receptors in platelets and megakaryocytes may alter platelet homeostasis leading to thrombocytosis $[15,16]$. Finally, a recent study showed that baricitinib down-regulated IL-6- and IL-12-dependent inflammatory pathways, but left interferon levels unaffected, which may transmit the strongest prothrombotic signals [17]. The imbalance in thrombotic events with baricitinib 4-mg dose in clinical trials [13] prompted the FDA to approve the lower 2-mg dose in patients with rheumatoid arthritis.

Rajasimhan, Suraj (NIH/CC/PHAR) [E] < suraj.rajasimhan@nih.gov>

Pamuk, Omer (NIH/NIAMS) [E] <omer.pamuk@nih. gov>

Katz, James (NIH/NIAMS) [E] <james.katz@ nih.gov>

\section{Declarations}

Funding The research to which this correspondence refers was supported by the Intramural Research Program of the National Institutes of Health, National Institute of Arthritis and Musculoskeletal and Skin Diseases.

Conflict of interest The NIH, but not the authors of this letter, reports the following disclosure statement: The National Institutes of Health holds patents on targeting JAKs. NIAMS and Pfizer have a Collaborative Research and Development Award (CRADA). However, the authors have no direct involvement in these patents or awards.

Ethics approval Not applicable.

Consent to participate Not applicable.

Consent for publication Not applicable.

Availability of data and materials Not applicable.

Code availability Not applicable.

Author contributions All authors contributed to the writing of this letter.

Open Access This article is licensed under a Creative Commons Attribution-NonCommercial 4.0 International License, which permits any non-commercial use, sharing, adaptation, distribution and reproduction in any medium or format, as long as you give appropriate credit to the original author(s) and the source, provide a link to the Creative Commons licence, and indicate if changes were made. The images or other third party material in this article are included in the article's Creative
Commons licence, unless indicated otherwise in a credit line to the material. If material is not included in the article's Creative Commons licence and your intended use is not permitted by statutory regulation or exceeds the permitted use, you will need to obtain permission directly from the copyright holder. To view a copy of this licence, visit http://creativecommons.org/licenses/by-nc/4.0/.

\section{References}

1. Moura CA, Rosa FS, Assis LH, Moura CG. Comment on "safety of Janus kinase inhibitors in older patients: a focus on the thromboembolic risk". Drugs Aging. 2021. https://doi.org/10.1007/ s40266-021-00857-3.

2. Rajasimhan S, Pamuk O, Katz JD. Safety of Janus kinase inhibitors in older patients: a focus on the thromboembolic risk. Drugs Aging. 2020;37(8):551-8. https://doi.org/10.1007/s40266-020-00775-w.

3. Giménez Poderós T, Gallardo Borge S, Vazquez-Ferreiro P. Risk of venous thromboembolism associated with tofacitinib and baricitinib: a systematic review and indirect meta-analysis. Pharmacotherapy. 2020;40(12):1248-64. https://doi.org/10.1002/phar.2472.

4. Yates M, Mootoo A, Adas M, Bechman K, Rampes S, Patel V, et al. Venous thromboembolism risk with JAK inhibitors: a Meta-analysis. Arthritis Rheumatol. 2020. https://doi.org/10.1002/art.41580.

5. Mohamed MF, Beck D, Camp HS, Othman AA. Preferential inhibition of JAK1 relative to JAK3 by upadacitinib: exposure-response analyses of ex vivo data from 2 phase 1 clinical trials and comparison to tofacitinib. J Clin Pharmacol. 2020;60(2):188-97. https://doi. org/10.1002/jcph.1513.

6. Zhang X, Chua L, Ernest C 2nd, Macias W, Rooney T, Tham LS. Dose/exposure-response modeling to support dosing recommendation for phase III development of baricitinib in patients with rheumatoid arthritis. CPT Pharmacometrics Syst Pharmacol. 2017;6(12):804-13. https://doi.org/10.1002/psp4.12251.

7. Vallejo-Yagüe E, Weiler S, Micheroli R, Burden AM. Thromboembolic safety reporting of tofacitinib and baricitinib: an analysis of the WHO VigiBase. Drug Saf. 2020;43(9):881-91. https://doi.org/ 10.1007/s40264-020-00958-9.

8. Jaiswal S, Fontanillas P, Flannick J, Manning A, Grauman PV, Mar BG, et al. Age-related clonal hematopoiesis associated with adverse outcomes. N Engl J Med. 2014;371(26):2488-98. https://doi.org/10. 1056/NEJMoa1408617.

9. Steensma DP, Bejar R, Jaiswal S, Lindsley RC, Sekeres MA, Hasserjian RP, et al. Clonal hematopoiesis of indeterminate potential and its distinction from myelodysplastic syndromes. Blood. 2015;126(1):9-16. https://doi.org/10.1182/blood-2015-03-631747.

10. Savola P, Lundgren S, Keränen MAI, Almusa H, Ellonen P, Leirisalo-Repo M, et al. Clonal hematopoiesis in patients with rheumatoid arthritis. Blood Cancer J. 2018;8(8):69. https://doi.org/10.1038/ s41408-018-0107-2.

11. Perner F, Perner C, Ernst T, Heidel FH. Roles of JAK2 in aging, inflammation, hematopoiesis and malignant transformation. Cells. 2019;8(8):854. https://doi.org/10.3390/cells8080854.

12. Veninga A, De Simone I, Heemskerk JWM, Cate HT, van der Meijden PEJ. Clonal hematopoietic mutations linked to platelet traits and the risk of thrombosis or bleeding. Haematologica. 2020;105(8):2020-31. https://doi.org/10.3324/haematol.2019. 235994.

13. Kotyla PJ, Engelmann M, Giemza-Stokłosa J, Wnuk B, Islam MA. Thromboembolic adverse drug reactions in Janus Kinase (JAK) inhibitors: does the inhibitor specificity play a role? Int J Mol Sci. 2021;22(5):2449. https://doi.org/10.3390/ijms22052449.

14. Smolen JS, Genovese MC, Takeuchi T, Hyslop DL, Macias WL, Rooney T, et al. Safety profile of baricitinib in patients with active rheumatoid arthritis with over 2 years median time in treatment. 
J Rheumatol. 2019;46(1):7-18. https://doi.org/10.3899/jrheum. 171361.

15. Ng AP, Kauppi M, Metcalf D, Hyland CD, Josefsson EC, Lebois M, et al. Mpl expression on megakaryocytes and platelets is dispensable for thrombopoiesis but essential to prevent myeloproliferation. Proc Natl Acad Sci USA. 2014;111(16):5884-9. https://doi.org/10.1073/ pnas. 1404354111.

16. Meyer SC, Keller MD, Woods BA, LaFave LM, Bastian L, Kleppe $\mathrm{M}$, et al. Genetic studies reveal an unexpected negative regulatory role for Jak2 in thrombopoiesis. Blood. 2014;124(14):2280-4. https://doi.org/10.1182/blood-2014-03-560441.

17. Dörner T, Tanaka Y, Petri MA, Smolen JS, Wallace DJ, Dow ER, et al. Baricitinib-associated changes in global gene expression during a 24-week phase II clinical systemic lupus erythematosus trial implicates a mechanism of action through multiple immune-related pathways. Lupus Sci Med. 2020;7(1):e000424. https://doi.org/10. 1136/lupus-2020-000424. 